\title{
Agglomeration and Government Spending
}

\author{
STEVEN BRAKMAN, HARRY GARRETSEN \\ and CHARLES VAN MARREWIJK*
}

Revised: September 2005, Second revision February 2006,

Third revision, November 2006

Forthcoming in: S. Brakman and H. Garretsen (eds.), Recent Developments in

International Trade: Globalization and the Multinational Enterprise, MIT Press

\begin{abstract}
It is widely believed that globalization, through increased factor mobility, will exert a downward pressure on tax rates and hence on public expenditures. Recent advances in the new economic geography (NEG) literature have, however, shown that such a 'race to the bottom' is not inevitable. Even with perfect factor mobility, a positive tax differential between core and peripheral countries can persist as long as the agglomeration rent, that is associated with being located in the agglomeration, exceeds the tax gap. In these NEG models the relevance of government spending as a determinant of agglomeration is, however, unduly neglected. The focus is on tax rates only and on the stability of core-periphery equilibria. Using a NEG model where the provision of public goods is allowed to influence the location choices of economic agents and starting intially from a spreading instead of a core-periphery equilibrium, we show that governments can affect the spatial equilibrium through their provision of public goods. Our main finding is that the introduction of public goods fosters agglomeration in the sense that it makes the spreading equilibrium unstable.
\end{abstract}

JEL Code: H10, F12, F15 


\section{Introduction}

Tax harmonization is high on the political agenda of the EU-countries. It is widely believed that with the arrival of the Economic and Monetary Union (EMU) and with "globalization" in general the EU-countries are forced to harmonize taxes. The standard reasoning is that in the absence of a policy of tax harmonization full-fledged economic integration in the EU will lead to a 'race to the bottom'. For the EU, Sinn (1990) has aptly summarized this line of reasoning. A race to the bottom would mean that in a truly common market in the EU, the mobile factors of production (in particular high-skilled labor and capital) will locate in the country with the lowest tax rate, with the result that all EU-countries are forced to adopt this tax rate. In other words, economic integration could go along with fierce tax competition between the EU-countries. This is thought to be harmful because it would imply a sub-optimal provision of public goods. To avoid this unwanted outcome, a policy of tax harmonization is deemed necessary. However, taxes are only part of the story: location specific government expenditures, which affect the quality of a country's social and economic infrastructure, also determine the attractiveness of a location.

The recent new economic geography literature leads potentially to very different conclusions with respect to tax competition and harmonization (Baldwin et al, 2003). In a much-debated paper, Baldwin and Krugman (2004) show that there is no need for a race to the bottom to begin with and that a policy of tax harmonization could make all countries worse off. The main idea is that economic integration could lead to a core-periphery outcome, with an agglomeration rent for the production factors located in the core, reflecting the fact that the production factors earn more (in real terms) in the core than in the periphery. The rent can be taxed and this allows the core countries to have a higher tax rate than the peripheral countries (see also Andersson and Forslid, 2003). Tax competition thus does not need to lead to a race to the bottom, which is important because it corresponds with the observed lack of a race to the bottom in reality.

Although the contributions of Baldwin and Krugman (2004), and Andersson and Forslid (2003) challenge the standard views about the race to the bottom, their treatment of the government sector is rather rudimentary, emphasizing taxes and not the productive effects of public expenditures on the economy which is also used as a 
policy instrument in order to increase the attractiveness of a region. ${ }^{1}$ Furthermore, these studies concentrate on the agglomeration equilibrium and analyze the relationship between the agglomeration rent and the tax gap between core and periphery. In doing so, the focus is on the conditions under which the agglomeration equilibrium is stable (that is to say, the sustain (and not the break) analysis in NEG terminology is central).

Public regional expenditure, however, is potentially very important. During the European Council meeting of the EU in Lisbon in March 2000, for example, the EU member states agreed upon a (benchmarking) method to determine the competitiveness of the EU economies using no less than 54 indicators, with emphasis on the quality of the social and economic infrastructure. Keen and Marchand (1997) use a simpler model in which agglomeration economies play no role and explore a government's choice of type of public expenditures (public input to production versus public consumption good) and show that similar incentives as discussed below lead to a bias in favor of public inputs. Similarly, Brülhart and Trionfetti (2004) show that (biased) public expenditures can influence a country's specialization pattern.

When the effects of agglomeration are thought to be important, tax and spending policies represent two opposing forces. All other things remaining the same, higher taxes stimulate spreading even though the existence of an agglomeration rent may prevent the spreading from actually taking place. Similarly, an increase in public spending stimulates agglomeration if this spending enhances the attractiveness of the location for the mobile factors of production. ${ }^{2}$ But all things do not remain the same in the sense that higher taxes typically also imply higher public spending and vice versa. The extent to which a larger government sector (meaning higher public spending and taxes) really leads to a better quality of the country's infrastructure is an issue that has troubled EU policy-makers for a long time.

In this paper we extend the Baldwin and Krugman (2004) and Andersson and Forslid (2003) approach in three ways. First, we allow for public spending to affect the cost of production, which has an impact on the location decisions of firms and workers. Second, we also take into account that the public sector competes with the private sector on the labor market so that public spending takes up net resources. Third, in our 
analysis we focus on the symmetric equilibrium, as opposed to the core-periphery or agglomeration equilibrium (as in Baldwin and Krugman, 2004), and thereby on the impact of the provision of public goods on the symmetric equilibrium. The present paper focuses on the interdependencies between taxes and government spending from a production cost perspective, see Brakman, Garretsen, and van Marrewijk (2002) for a discussion of the relation between government spending and consumption externalities. At this stage, it is important to note what we do not do. We do not analyze locational competition in which optimizing governments compete - often in a Nash setting - for mobile factors of production. This would require a discussion of what it is that governments optimize and in what type of game they are involved (cooperative or non-cooperative). These important issues require a separate paper.

The paper is organized as follows. Section 2 briefly presents some stylized facts for the EU about cross-country differences in corporate rate income taxation, public spending, location indicators and the corresponding differences in location decisions. Section 3 presents the 2-region new economic geography model, the so called ForslidOttaviano model with the addition of a more elaborate government sector. In section 4 we analyze the impact of the (symmetric) introduction of public goods on the key variables in our model. Section 5 conducts a break analysis. That is to say, for a given level of public goods we analyze when the symmetric equilibrium becomes unstable. The outcome is also compared with the benchmark of no public goods provision. In section 6 we present some simulations to illustrate how the introduction of public goods may affect the equilibrium distribution of the footloose factor of production (capital) between the 2 countries. Section 7 summarizes and concludes. Our main finding is that the introduction of our version of public goods fosters agglomeration.

\section{Stylized facts about taxation and public spending in the EU}

We first illustrate that a race to the bottom in the EU is not inevitable. We concentrate on the taxation of capital because in our model we assume that capital is mobile and labor is not. This is in accordance with the often-observed higher degree of capital

\section{Table 1 Placed here}


mobility as compared to labor mobility. For the EU countries, Table 1 shows the development of corporate income taxes for the period 1990-1999, an era of increasing economic integration. These tax rates differ from the "nominal" tax rates as they take into account the implications of differences in tax base, allowances for depreciation, etc. that exist between EU-countries. The reported data are based on financial accounts of individual firms.

Table 1 offers no conclusive evidence, but a number of things are worth pointing out:

- The large countries of the EU (Germany, the UK, France and Italy) clearly have an above-average tax rate. ${ }^{3}$

- The smaller and "peripheral" countries (Greece, Portugal and Spain) started out with a below-average tax rate, but their corporate income tax rates clearly increased during the 1990s. Ireland is a notable exception.

- The average EU corporate income tax rate is fairly constant through time, in any case shows no discernible downward trend.

- The standard deviation has strongly decreased from 1990 to 1999 , so there is some tax rate convergence, but not towards the lowest rate

These four observations offer some (preliminary) support for the lack of a race to the bottom. Core/large countries persistently have higher tax rates and small/peripheral countries even display some "catching up" in terms of their tax rates. ${ }^{4}$ Measuring the effective corporate income tax burden for firms is, however, not an easy task and the findings shown in Table 1 are not undisputed. It is clear that for almost every OECD country statutory income tax rates have come down from the 1980s onwards. With respect to effective tax rates, the seminal study by Devereux, Griffith and Klemm (2002) concludes that effective marginal rates have remained rather stable whereas effective average tax rates have come down. Even if corporate income tax rates have decreased, the tax base has invariably been broadened with the result that for most countries tax revenues on corporate income as a percentage of GDP have been more or less stable since 1965 (Devereux et al, 2002, p. 487). Be that as it may, these findings are in line with those in Table 1 to the extent that they are both at odds with the predictions that follow from the standard tax competition literature and pose questions as to the relevance of the race to the bottom hypothesis. ${ }^{5}$ In related empirical work, and taking the NEG literature into account, Krogstrup (2004) and 
Garretsen and Peeters (2006) find that capital mobility puts (at most) a limited downward pressure on corporate tax rates but also that core or more centrally located countries typically have a higher corporate tax rate.

\section{Table 2 Placed here}

Next, we turn to government spending, see Table 2. Baldwin and Krugman (2004) explain the lack of a race to the bottom for taxation in the EU by the fact that despite higher tax rates, the after tax income in the core EU countries is still larger than in the more peripheral EU countries due to a positive agglomeration rent. These rents are the result of positive pecuniary externalities. By looking only at taxation, government policy either has no impact at all on the location of economic activity as long as the tax rate is not too high or, if the tax rate exceeds a specific threshold, the agglomeration equilibrium can no longer be sustained. A core country can thus afford a higher tax rate, but in essence taxation is a potential spreading force. Government policies then, in principle, do not contribute to the agglomeration forces. However, we stress that public spending is an essential part of the story and that government policies can increase the attractiveness of a country. ${ }^{6}$

Table 2 illustrates that, with respect to government spending, the EU-countries are not involved in a race to the bottom. It shows that for most EU countries there is no downward trend in (central) government expenditures as a percentage of GDP. This is certainly true for the core EU-countries: Germany, France and the UK. Furthermore, in some of the peripheral EU-countries there is an increase in this expenditure ratio. Again, there are marked cross-country differences, but there is no evidence of a race to the bottom.

\section{Table 3 Placed here}

Benchmarking has been a popular method recently among EU-policymakers to compare the relative location advantages of the EU-countries and regions for the mobile factors of production. If we take North-West Europe as an example, the Dutch Ministry of Economic Affairs has identified the regions in Table 3 as having the most attractive location characteristics. The table indicates that the attractiveness is to some 
extent thought to be the result of (past) regional public spending. The table lists just a few reasons why some regions are preferred locations, but it does suggest that location decisions can be affected by regional government spending on, for example, infra-structure and not only by the levels of taxation. This last point also comes across from an UNCTAD survey on location and foreign direct investment (UNCTAD, 1996). Large companies like Samsung or Daimler-Chrysler stated that, apart from taxes and subsidies, the social and economic infrastructure (transports) are key determinants for their location decisions. To show this point formally we now turn to the model.

\section{The Model}

We extend the analytically solvable model developed by Forslid (1999), Ottaviano (2001), and Forslid and Ottaviano (2001, 2003), henceforth referred to as the ForslidOttaviano model, by including a more detailed analysis of the government sector, incorporating government spending effects, the efficiency of government production, and competition between the government and the private sector on the labor market. The reason to use this analytically solvable model is twofold. First, in the discussion of tax competition the main issue is that mobile and immobile factors of production react differently to taxation. Below we will call the immobile factor labor and the mobile factor capital. In the European context this corresponds to the fact that labor is less mobile than capital. As argued by Ottaviano (2001) it is realistic to assume that the manufacturing or modern sector uses both skilled and unskilled labor to produce its output. ${ }^{7}$ The ability to distinguish between mobile and immobile factors in the manufacturing sector is also why Baldwin and Krugman (2004) and Andersson and Forslid (2003) take this model as the starting point in their analyses of tax competition and economic integration. A second reason to use the model is that it can be solved analytically, which enables us to derive some analytical results.

There are two regions $(j=1,2)$. Each region has $L_{j}$ workers and $K_{j}$ capital. ${ }^{8}$ Capital can be thought of as human or knowledge capital. Workers are geographically immobile, whereas capital is mobile. Henceforth we make the following assumption:

- The two regions are identical with respect to the immobile factor of production, that is $L_{1}=L_{2}=0.5$. 
All agents have the same preferences, depending on the consumption of food $F$ and manufactures $M$, a composite of $n$ different varieties $c_{i}$ :

$$
\begin{aligned}
& U=M^{\delta} F^{(1-\delta)} ; \quad 0<\delta<1 \\
& M=\left(\sum_{i=1}^{n} c_{i}^{(\sigma-1) / \sigma}\right)^{\sigma /(\sigma-1)} ; \quad \sigma>1,
\end{aligned}
$$

where $\delta$ is the share of income spent on manufactures and $\sigma$ is the elasticity of substitution between different varieties of manufactures. The production of food, which is freely traded at zero transport costs, takes place under constant returns to scale and requires only workers. A suitable choice of units ensures that one unit of labor produces one unit of food. Labor is used in food production and in the variable cost part of production in the manufacturing sector. Using food as a numéraire and assuming free trade implies that its price, and hence the wage rate, can be set equal to one. This means that we only have to determine the return to capital, $r$.

Firms in the manufacturing industry use labor and capital to produce a variety of manufactures under increasing returns to scale. The fixed cost component represents the knowledge-intensive part of the manufacturing production process, such as R\&D, marketing and management. Both the fixed and variable cost components of production depend upon the quality of the infrastructure, education level, judicial system, police services, etc. All of these are related to the level of government spending $Z_{j}$. The reduction in costs is measured by the efficiency function $f_{j}\left(Z_{j}\right)$ with $f_{j}(0)=1, f_{j}{ }^{\prime} \leq 0$. This distinguishes our model from Andersson and Forslid (2003) and Baldwin and Krugman (2004). Let $r_{j}$ be the return to capital in region $j$, then the costs of producing $x$ units of a manufacturing variety in region $j$ are equal to (the choice of units, and the fact that the wage rate equals unity simplifies the notation below):

$$
f_{j}\left(Z_{j}\right)\left[r_{j}+[(\sigma-1) / \sigma] x\right]
$$

The production of public goods requires capital only under constant returns to scale. This is the second extension of our model: we assume that the production of public goods takes up net resources. It captures the idea that government production competes with private production and relates to the discussion about the optimal size 
of the government sector. Market clearing for capital in region $j$ allows us to determine the number of varieties produced in region $j$ :

$$
n_{j}=\left(K_{j}-Z_{j}\right) / f_{j}\left(Z_{j}\right)
$$

Note, that this equation differs from the standard equation in the NEG-literature that determines the number of varieties in the sense that the "fixed" costs are no-longer fixed in our variant of the model. Equation (4) reflects the fact that the private and public sector compete with each other on the labor market. Equilibrium in the public sector requires that the value of public spending is fully paid by taxes:

$$
r_{j} Z_{j}=t_{j} Y_{j}
$$

where $t_{j}$ is the uniform income tax rate that applies to both labor and capital. ${ }^{9}$ Given the sector distribution of capital and the return to capital, choosing a level of public goods determines the tax rate and vice versa. In addition we assume that capital employed in the public sector earns the same return as in the private sector. This reflects the notion that the public sector has to pay competing wages in order to attract capital.

Standard monopolistic competition mark-up pricing gives:

$$
p_{j}=f_{j}\left(Z_{j}\right)
$$

This pricing rule applies for locally produced and sold goods. Two observations with respect to this rule can be made. First, due to the production structure - see equation (3) - the price $p_{j}$ does not depend on wages. Second, we cannot choose units such that $p_{j}=1$ because the marginal cost of production are a function of the level of public goods $Z_{j}$ provided in region $j$. However, once we know the level of public goods provided, the local price level for manufacturing varieties is also determined.

Free entry and exit in the manufacturing sector ensures that profits are zero, which determines the equilibrium output per firm, see (7). Using our normalization of wages, the income in region $j$ is given in (8).

$$
\begin{aligned}
& \text { (7) } x_{j}=\sigma r_{j} \\
& \text { (8) } Y_{j}=r_{j} K_{j}+L_{j}
\end{aligned}
$$


Using Samuelson's (1952) iceberg transport costs $T$ (= the number of goods shipped from a region to ensure that 1 unit arrives in the other region) in the manufacturing sector, the price charged in the other region is $T$ times as high as the mill price. It is convenient to define the 'free-ness of trade' parameter $\phi$ as a function of transport costs and the elasticity of substitution: $\phi \equiv T^{1-\sigma}$. It ranges between 0 and 1 , where $\phi=0$ represents autarky and $\phi=1$ indicates free trade (no obstacles to the movement of manufacturing varieties of any kind whatsoever).

The manufacturing sector market clearing condition is standard and given by (note that we assume that civil servants have the same preferences as non-civil servants, so that the income term reflects total income)

$$
\begin{aligned}
& p_{j} x_{j}=\frac{p_{j}^{1-\sigma} \delta Y_{j}}{P_{j}^{1-\sigma}}+\frac{\phi p_{k}^{1-\sigma} \delta Y_{k}}{P_{k}^{1-\sigma}} \\
& P_{j}=\left(p_{j}^{1-\sigma} n_{j}+\phi p_{k}^{1-\sigma} n_{k}\right)^{1 /(1-\sigma)},
\end{aligned}
$$

where $P_{j}$ is the price index for manufactures in region $j$. The left-hand side of equation (9) gives the equilibrium (value of) output per firm and the right-hand side the associated demand coming from the home region, and from the distant region, which explains the transport cost term. Using equations (6), (7), (9), and (10) gives:

$$
\begin{aligned}
& r_{1}=\left(\frac{1}{f_{1} \sigma}\right)\left[\frac{f_{1}^{1-\sigma} \delta Y_{1}}{n_{1} f_{1}^{1-\sigma}+\phi n_{2} f_{2}^{1-\sigma}}+\frac{\phi f_{2}^{1-\sigma} \delta Y_{2}}{n_{2} f_{2}^{1-\sigma}+\phi n_{1} f_{1}^{1-\sigma}}\right] \\
& r_{2}=\left(\frac{1}{f_{2} \sigma}\right)\left[\frac{f_{2}^{1-\sigma} \delta Y_{2}}{n_{2} f_{2}^{1-\sigma}+\phi n_{1} f_{1}^{1-\sigma}}+\frac{\phi f_{1}^{1-\sigma} \delta Y_{1}}{n_{1} f_{1}^{1-\sigma}+\phi n_{2} f_{2}^{1-\sigma}}\right]
\end{aligned}
$$

In the sequel we let $\lambda$ denote the share of capital in region 1. As shown in Appendix I, the ratio of the rewards to capital is equal to:

$$
\frac{r_{1}}{r_{2}}=\frac{f_{2} \sigma\left[\phi n_{1}\left(1+\psi_{1}\right)+n_{2}\left(1+\phi^{2} \psi_{2}\right)\right]+\left(\phi^{2}-1\right)(1-\lambda) \delta}{f_{1} \sigma\left[\phi n_{2}\left(1+\psi_{2}\right)+n_{1}\left(1+\phi^{2} \psi_{1}\right)\right]+\left(\phi^{2}-1\right) \lambda \delta} ; \quad \psi_{j} \equiv f_{j}^{1-\sigma} / f_{k}^{1-\sigma}
$$

Once the functional form of the provision of public goods, see equation (3), is specified, in addition to a public policy rule determining the level of public goods, equation (12) can be explicitly written as a function of $\lambda$, the share of capital in region 1. 
To round up the discussion of our model, we note that the location decision of capital involves not only the factor rewards $r_{1}$ and $r_{2}$ but also the respective price levels, tax rates, and the provision of public services. The incentive of capital to re-locate is therefore determined by the ratio $\rho$ of indirect utilities (or welfare):

$$
\rho=\left(\frac{\left(1-t_{1}\right) r_{1}}{\left(1-t_{2}\right) r_{2}}\right)\left(\frac{P_{2}}{P_{1}}\right)^{\delta}
$$

This ratio is central in the analysis in the next sections. Apart from the case of complete agglomeration, capital has no incentive to re-locate if welfare is the same in the two regions $(\rho=1)$, while capital moves from region 2 to region 1 if welfare is higher in region $1(\rho>1)$ and from region 1 to region 2 if welfare is lower in region 1 $(\rho<1)$. This completes our discussion of the model.

\section{Analysis of the symmetric equilibrium for a given level of public goods}

Extending the Forslid-Ottaviano model, in which the manufacturing sector uses both a mobile and an immobile production factor, not only allows us to analyze and illustrate locational competition, but also enables us to derive some analytical results. In doing so, we focus attention on the analysis of the symmetric equilibrium, that is if both regions provide the same level of public goods and attract the same share of capital. This is another difference with for instance Baldwin and Krugman (2004) who build their analysis on the case of the agglomeration equilibrium, the case where all footloose economic activity is located in one country. Here, we ask a different question: what happens to the stability of the symmetric or no-agglomeration equilibrium once we allow for public goods? In particular, we want to know if agglomeration becomes more likely or not, see section 5 .

\section{Assumption 1}

- The two regions have a constant and given level of public goods $Z_{1}=Z_{2}=Z$.

- The influence of government spending on the cost of production in the two regions are identical: $f_{1}=f_{2}=f$.

Proposition 1 (spreading). Under assumption 1, the impact of public goods on the symmetric equilibrium is summarized in Table 4 (see appendix II). 


\section{Table 4 Placed here}

The impact of the standard new economic geography parameters on the spreading equilibrium is not surprising: an increase in the free-ness of trade parameter has no direct effect on most variables as measured relative to the numéraire, but of course reduces the price index (as more manufactured goods arrive at their destination) and thus increases real income and the real return to capital (and labor). As the free-ness of trade increases beyond a certain level the symmetric equilibrium will become unstable, see also below. An increase in the elasticity of substitution increases competition between varieties, which therefore reduces the return to capital and thus income. In addition, an increase in the ease with which consumers can substitute between different varieties reduces the price index. ${ }^{10}$ An increase in the share of income spent on manufactures increases the importance of capital relative to labor and thus increases the return to capital and income.

Increasing the provision of public goods reduces the cost of production (and thus the price) of an individual variety, and (through the increased scarcity of capital) increases the return to capital and income. All of this comes at the costs of an increased tax rate because the government has to pay competitive returns to capital. Since the share of capital allocated to the production of manufactures decreases while at the same time the "waste" in terms of the fixed cost to produce varieties decreases, the net effect on the number of varieties produced and on the price index is unclear. Enlarging the government sector is therefore a mixed blessing, the wisdom of which depends on the particular circumstances. If the production of public goods has a large enough impact on reducing the costs of production, the improved efficiency of the economy is beneficial through a reduction in the price of a variety and the price index and through an increase in the number of varieties produced (love-of-variety effect, see Brakman, Garretsen, and Van Marrewijk (2001, ch. 7)).

Note that under assumption 1 the terms $\psi_{j}$ defined in equation (12) are equal to 1 , which therefore simplifies to: 


$$
\begin{aligned}
& \frac{r_{1}}{r_{2}}=\frac{b_{1}(1-\lambda)+b_{2} \lambda-b_{3} Z}{b_{1} \lambda+b_{2}(1-\lambda)-b_{3} Z} \equiv h_{2}(\lambda \mid Z) ; \quad \text { where } \\
& b_{1} \equiv \sigma\left(1+\phi^{2}\right)-\delta\left(1-\phi^{2}\right) ; \quad b_{2} \equiv 2 \phi \sigma ; \quad b_{3} \equiv \sigma(1-\phi)^{2}
\end{aligned}
$$

The function $h_{2}(\lambda \mid Z)$ is defined for future reference. ${ }^{11}$ As the notation clarifies, the return to capital is a function of the share $\lambda$ of capital located in region 1 , given the level of public goods $Z$ produced in each region. The direction of the impact of the provision of public goods on the ratio of rewards to capital is readily determined. And gives us proposition 2 .

Proposition 2 (magnification I). If, for a given distribution of capital under assumption 1, region 1 has a higher reward to capital than region 2 in the absence of public goods, an equal provision of public goods in both regions magnifies the relatively higher reward to capital in region 1.

Similarly, using the above conditions, the relative price index $P_{2} / P_{1}$ simplifies to:

$$
\frac{P_{2}}{P_{1}}=\left(\frac{(1-\lambda)+\phi \lambda-(1+\phi) Z}{\lambda+\phi(1-\lambda)-(1+\phi) Z}\right)^{1 /(1-\sigma)}
$$

Again, the direction of the impact of the provision of public goods on the relative price ratio can be readily determined.

Proposition 3 (magnification II). If, for a given distribution of capital under assumption 1, region 2 has a higher price index than region 1 in the absence of public goods, an equal provision of public goods in both regions magnifies the relatively higher price index of region 2.

Obviously, if a higher return to capital in a particular region (for instance $r_{1}>r_{2}$ ) is also associated with a higher price index in that region $\left(P_{1}>P_{2}\right)$, the combination of propositions 2 and 3 shows that the net effect on the real rate of return to capital of the introduction of public goods depends on the relative magnitude of the impact on the rate of return compared to the impact on the price index. In the core geographical economics model upon which the Forslid-Ottaviano model is based, it is typically true that the region with a larger share of the mobile factor of production (say, region 1) would have a higher return to capital $\left(r_{1}>r_{2}\right)$ as well as a lower price index $\left(P_{1}<P_{2}\right)$ in 
which case the introduction of public goods would unambiguously foster agglomeration.

\section{Break analysis for a given level of public goods}

Based on the propositions derived in the previous section and our simulation results below, the introduction of productive public goods increases the possibilities for active government intervention by fostering agglomeration of manufacturing production rather than spreading of manufacturing production. This section formally addresses this question by analyzing the stability of the symmetric spreading equilibrium. In particular, we will determine for which value of the free-ness of trade parameter $\phi$ spreading of manufacturing production is no longer a stable equilibrium.

First, we note that, since there is an equal provision of public goods in both regions, the welfare ratio for capital given in equation (13) simplifies to:

$$
\begin{aligned}
& \rho(\lambda \mid Z)=\frac{\left(1-t_{1}\right)}{\left(1-t_{2}\right)} \frac{r_{1}}{r_{2}}\left(\frac{P_{2}}{P_{1}}\right)^{\delta} \equiv h_{1}(\lambda \mid Z) h_{2}(\lambda \mid Z) h_{3}(\lambda \mid Z), \text { where } \\
& h_{1}(\lambda \mid Z) \equiv \frac{\left(1-t_{1}\right)}{\left(1-t_{2}\right)}, \quad h_{2}(\lambda \mid Z) \equiv \frac{r_{1}}{r_{2}}, \quad h_{3}(\lambda \mid Z) \equiv\left(\frac{P_{2}}{P_{1}}\right)^{\delta}
\end{aligned}
$$

At the symmetric equilibrium $\lambda=0.5$ we have

$$
\begin{aligned}
& h_{1}(0.5 \mid Z)=h_{2}(0.5 \mid Z)=h_{3}(0.5 \mid Z)=1 \text { such that } \\
& \rho^{\prime}(0.5 \mid Z)=h_{1}^{\prime}(0.5 \mid Z)+h_{2}^{\prime}(0.5 \mid Z)+h_{3}^{\prime}(0.5 \mid Z)
\end{aligned}
$$

\section{Figure 1 Placed here}

Using this notation the break analysis consists of finding values of $\phi$ for which $\rho^{\prime}=0$. As shown in appendix III for the real rental rate this implies solving equation (16).

$$
\frac{4 \delta(1-\phi)}{(\sigma-1)(1+\phi)(1-2 Z)}-\frac{4\left(\sigma\left(1+\phi^{2}\right)-\delta\left(1-\phi^{2}\right)-2 \phi \sigma\right)}{\left[\sigma\left(1+\phi^{2}\right)-\delta\left(1-\phi^{2}\right)+2 \phi \sigma-2 \sigma(1-\phi)^{2} Z\right]}=0
$$

Let $\bar{\phi}$ be the solution to equation (16) if there are no public goods provided, that is if $Z=0$ (see appendix III). We can determine the impact of the introduction of public goods on the break condition at the margin, that is, the solution evaluated at $Z=0$, $\lambda=0.5$, and $\phi=\bar{\phi}$. Appendix III shows that at the margin the break condition for the free-ness of trade parameter falls if, and only if, condition (17) holds. 


$$
\bar{\phi}(\delta \bar{\phi}+4 \sigma)>\delta
$$

Proposition 4 (break point). Under assumption 1, the introduction of an equal provision of public goods in both regions at the margin reduces the free-ness of trade index for the break-point if, and only if, condition (17) holds.

\section{Figure 2 Placed here}

Proposition 4 is illustrated if condition (17) holds in Figure 1, showing that the breakpoint is reached for a lower value of the free-ness of trade parameter $\varphi$ if there are public goods $(Z=0.1)$ than in the absence of public goods $(Z=0)$. Since condition (17) is rather weak and holds for a wide range of parameter combinations $(\delta, \sigma)$, the introduction of public goods usually leads to a fall in the free-ness of trade breakpoint, tending to reduce the stability of the spreading equilibrium, as illustrated in Figure 2. For Europe, for example, this suggests that incorporating the impact of the provision of public goods on the stability of the economic process, the process of continued economic integration (EU enlargement), which increases the free-ness of trade parameter $\phi$, is more likely to lead to instability of the spreading equilibrium, or equivalently more likely to result in core-periphery outcomes. Figure 1 also illustrates why this is the case: $h^{\prime}{ }_{3}>0$ and this indicates that the additional provision of public goods represents a negative externality as it reduces the number of available varieties, this implies that for lower values of the free-ness of trade index the incentive to move to a (marginal) larger region (more varieties) is reached sooner than without public goods. The next section illustrates our findings by showing a few simulation results. It shows (again) that the introduction of public goods stimulates agglomeration and that this is the case for all intermediate values of the free-ness of trade parameter $\phi$.

\section{Simulation results}

Before we show some simulation examples we first have to address the following question: what is a reasonable choice for the tax rate to use in our simulations? We apply the following motivation to be able to answer this question. The government maximizes $(1-t) r$, taking into consideration that $r$ is a function of the tax rate $t$, and assumes that the change in remuneration is directly proportional to the change in capital productivity in the manufacturing sector (thus ignoring price index effects). 
The first order condition implies that the government sets the income tax rate such that $1 /(1-t)=r^{\prime} / r=-f^{\prime} / f$. If we choose $f(Z)=\exp (-\eta Z)$, we have $1 /(1-t)=\eta$, which we use in the simulations below.

\section{Figure 3 Placed here}

First, Figure 3 illustrates for $Z_{1}=Z_{2}=0$ (no public goods), that around the break-point the symmetric equilibrium is stable (the break point occurs at $\phi=0.359$ ). Introducing public goods (squared line) in both countries $\left(\mathrm{Z}_{1}=\mathrm{Z}_{2}=0.1\right)$ has a strong effect on the stability of the symmetric equilibrium in the sense that it becomes unstable. This simulation result is in line with the analytical results from the previous section. In section 5 we showed that for a broad range of parameter values, in particular for a broad range of $\sigma$ and $\delta$ [see condition (17) and Figure 2], the introduction of public goods stimulates agglomeration by making the spreading equilibrium unstable at a higher level of trade costs (lower values for $\phi$ ). It is only for a sufficiently low elasticity of substitution $\sigma$ and a sufficiently high share of income spent on manufactures $\delta$ that this is not the case. To illustrate this, we ran the same simulation as in Figure 3, but now with $\sigma=2$ and $\delta=0.8$ (not shown here), and just like Figure 2 predicts the introduction of public goods now strengthens the stability of the spreading equilibrium.

The analytical results derived in the previous section are based on the assumption that the 2 countries or regions are symmetric w.r.t. the provision of public goods: $Z_{1}=Z_{2}$. Figure 4 shows a simulation where we dropped this assumption. In Figure 4 we compare the situation where the provision of public goods in country 1 is the same as in country $2, Z_{1}=0.05$, and the situation when the provision of public goods is higher, $\mathrm{Z}_{2}=0.07$.

\section{Figure 4 Placed here}

If the 2 countries have the same level of public goods (dotted line) we end up with a stable symmetric equilibrium where both countries thus have the same share of capital of 0.5 . For the case where $Z_{1}>Z_{2}$ (squared line), country 1 ends up with a higher share 
of capital $\lambda$ than country 2. The stable equilibrium now is one of partial agglomeration: $\lambda_{1}>\lambda_{2}$. This simulation result suggests that for countries to attract a larger share of the mobile production factor, they need to make sure that they provide more public goods. This is interesting because a relatively higher level of the provision of public goods is associated with higher tax levels. The positive effects of public goods dominate in this case.

One might be tempted to conclude that tax competition would lead to a race-to-thetop with respect to taxation and public expenditures, where in the end all of a country's productive resources are directed towards the public goods sector. This is, however, not what our model predicts. A relatively higher level of public goods provision might be effective, as Figure 4 shows (in terms of attracting a more than a proportional share of capital), but a country can easily push this argument too far. This is illustrated in Figure 5, which gives the simulation results for the case where country 1 spends far more on public goods than country 2, but more public goods may imply that country 1's share of capital will be lower compared to the case with less public goods. In Figure 5, country 2 does not provide public goods at all $\left(\mathrm{Z}_{2}=0\right)$ and, in line with Figure 4, a moderate level of public goods provision by country 1 $\left(Z_{1}=0.1\right)$ makes country 1 better off to the extent that it ends up with more than its proportionate share of capital in equilibrium: $\lambda_{1}>0.5$ (see dotted line). When, however, country 1 decides to increase the production of public goods, the resulting equilibrium is such that there is no longer partial agglomeration in favour of country 1. Stronger still, its share of capital could even drop below 0.5 as Figure 5 illustrates for $\mathrm{Z}_{1}=0.3$ (squared line).

As in all NEG models (partial) agglomeration is the result of the balance between spreading and agglomerating forces. In the present NEG model the production of public goods has negative effects that may outweigh the benefits of public goods. The relative welfare $\rho$ for capital in country 1 is for instance negatively affected by an increased tax rate or the reduction of the number of varieties of the manufacturing good, both of which result when the level of public goods is increased. This important cautionary note as to the benefits of a relative increase in the level of public goods by, here, country 1 is reinforced if we would also allow for another asymmetry between the 2 countries, a country-specific efficiency of of public goods production 
$f_{i}(Z)=\exp \left(-\eta_{i} Z\right)$ by making $\eta_{i}$ country specific, see Brakman, Garretsen, and van Marrewijk (2002).

\section{Figure 5 Placed here}

\section{Summary and conclusions}

Recent advances in the theory of trade and location have shown that increasing economic integration does not need to lead to a race to the bottom with respect to taxation. This important result challenges the standard views about tax competition but the treatment of the government sector is still rather rudimentary. The emphasis is almost exclusively on taxes and its distribution consequences. This is rather one-sided because taxes are a means to an end and tax-financed public spending can also be used an instrument of locational competition. Countries try to increase their attractiveness as a location by investing in location-specific infrastructure. When the effects of agglomeration are thought to be important tax and spending policies represent two opposing forces. All other things remaining the same, higher taxes stimulate spreading even though the existence of an agglomeration rent may prevent the spreading from actually taking place. Similarly, an increase in public spending stimulates agglomeration if this spending enhances the attractiveness of the location for the mobile factors of production. But all things do not remain the same in the sense that higher taxes typically also imply higher public spending and vice versa.

In the present paper we extend recent work in the new economic geography literature on tax competition by Baldwin and Krugman (2004) and Andersson and Forslid (2003) in three ways. First, we allow for public spending to affect the cost of production and this has an impact on the location decisions of firms and workers. Second, we also take into account that the public sector has to compete with the private sector on the labor market so that public spending takes up net resources. Thirdly, in our analytics we focus on the symmetric equilibrium, as opposed to the agglomeration equilibrium, and on the impact of the provision of public goods on the symmetric equilibrium. 
The main contribution of this paper is that it takes the interdependency between taxes and spending as a starting point. This means that by restricting locational competition to tax competition only, one neglects that the provision of public goods also determines (positively or negatively) the attractiveness of locations for footloose economic activity and thereby determines the equilibrium with respect to the distribution of footloose factors of production across space. Our conclusions are based on simulation results as well as analytical results. In general, the results indicate that, starting from an initial symmetric equilibrium, the introduction of public goods stimulates agglomeration and that, compared to the "no public goods" case, the symmetric equilibrium becomes unstable for lower degrees of economic integration (higher trade costs). Our simulations not only back up our analytical results, but by allowing for an asymmetric provision of public goods between the 2 countries, they additionally show that there's a limit up to which an increase in public goods provision stimulates (partial) agglomeration. 


\section{Appendix I Derivation of equation (12)}

Using the income equations (8), equations (11) can be written as

$$
\begin{aligned}
& r_{1}=\left(\frac{1}{f_{1} \sigma}\right)\left[\frac{f_{1}^{1-\sigma} \delta\left(r_{1} K_{1}+L_{1}\right)}{n_{1} f_{1}^{1-\sigma}+\phi n_{2} f_{2}^{1-\sigma}}+\frac{\phi f_{2}^{1-\sigma} \delta\left(r_{2} K_{2}+L_{2}\right)}{n_{2} f_{2}^{1-\sigma}+\phi n_{1} f_{1}^{1-\sigma}}\right] \\
& r_{2}=\left(\frac{1}{f_{2} \sigma}\right)\left[\frac{f_{2}^{1-\sigma} \delta\left(r_{2} K_{2}+L_{2}\right)}{n_{2} f_{2}^{1-\sigma}+\phi n_{1} f_{1}^{1-\sigma}}+\frac{\phi f_{1}^{1-\sigma} \delta\left(r_{1} K_{1}+L_{1}\right)}{n_{1} f_{1}^{1-\sigma}+\phi n_{2} f_{2}^{1-\sigma}}\right]
\end{aligned}
$$

Two linear equations in the unknowns $r_{1}$ en $r_{2}$ which can be solved analytically:

$$
\begin{aligned}
& \begin{array}{l}
r_{1}=a_{11} r_{1}+a_{12} r_{2}+d_{1} \\
r_{2}=a_{21} r_{2}+a_{22} r_{2}+d_{2}
\end{array} \Rightarrow\left[\begin{array}{l}
r_{1} \\
r_{2}
\end{array}\right]=\frac{1}{\left(1-a_{11}\right)\left(1-a_{22}\right)-a_{12} a_{21}}\left[\begin{array}{c}
\left(1-a_{22}\right) d_{1}+a_{12} d_{2} \\
a_{21} d_{1}+\left(1-a_{11}\right) d_{2}
\end{array}\right] \\
& \text { where } a_{11}=\left(\frac{1}{f_{1} \sigma}\right) \bar{h}_{1} K_{1} \quad a_{12}=\left(\frac{1}{f_{1} \sigma}\right) \phi \bar{h}_{2} K_{2} \quad a_{21}=\left(\frac{1}{f_{2} \sigma}\right) \phi \overline{h_{1}} K_{1} \\
& a_{22}=\left(\frac{1}{f_{2} \sigma}\right) \bar{h}_{2} K_{2} \quad d_{1}=\left(\frac{1}{f_{1} \sigma}\right)\left(\bar{h}_{1} L_{1}+\phi \bar{h}_{2} L_{2}\right) \quad d_{2}=\left(\frac{1}{f_{2} \sigma}\right)\left(\phi \bar{h}_{1} L_{1}+\bar{h}_{2} L_{2}\right) \\
& \bar{h}_{j} \equiv\left(\frac{f_{j}^{1-\sigma} \delta}{n_{j} f_{j}^{1-\sigma}+\phi n_{k} f_{k}^{1-\sigma}}\right)
\end{aligned}
$$

For $K=1, \quad K_{1}=\lambda, \quad L_{1}=L_{2}=1 / 2$ the derivation of $r_{i}$ is now straightforward

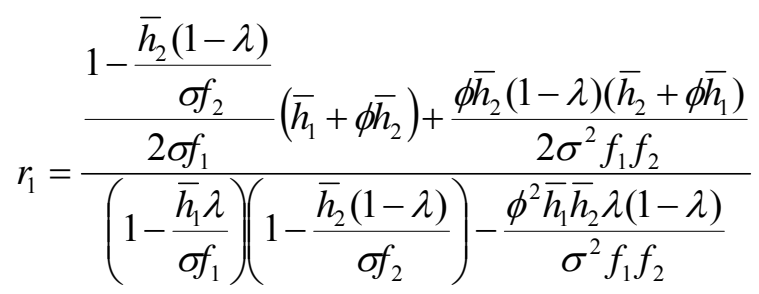

and similarly for $r_{2}$. Using the definitions of $\bar{h}_{j}$ and defining $\psi_{j}$ gives equation (14):

$$
\frac{r_{1}}{r_{2}}=\frac{f_{2} \sigma\left[\phi n_{1}\left(1+\psi_{1}\right)+n_{2}\left(1+\phi^{2} \psi_{2}\right)\right]+\left(\phi^{2}-1\right)(1-\lambda) \delta}{f_{1} \sigma\left[\phi n_{2}\left(1+\psi_{2}\right)+n_{1}\left(1+\phi^{2} \psi_{1}\right)\right]+\left(\phi^{2}-1\right) \lambda \delta} ; \quad \psi_{j} \equiv f_{j}^{1-\sigma} / f_{k}^{1-\sigma}, \quad j \neq k
$$

In the absence of a government sector, that is if $f_{1}=f_{2}=1$ (such that $\left.\psi_{1}=\psi_{2}=1\right)$ and $n_{1}=\lambda ; n_{2}=1-\lambda$, this expression simplifies to the Forslid-Ottaviano model:

$$
\frac{r_{1}}{r_{2}}=\frac{\sigma\left[2 \phi \lambda+(1-\lambda)\left(1+\phi^{2}\right)\right]+\left(\phi^{2}-1\right)(1-\lambda) \delta}{\sigma\left[2 \phi(1-\lambda)+\lambda\left(1+\phi^{2}\right)\right]+\left(\phi^{2}-1\right) \lambda \delta} \text {. }
$$




\section{Appendix II Derivation of Table 4}

At the symmetric equilibrium we have: $\lambda=0.5 ; \quad f_{1}=f_{2}=f ; \bar{h}_{1}=\bar{h}_{2}=\bar{h}$; $n_{1}=n_{2}=n$. Use this in appendix I to calculate the rental rate:

$\left.r_{1}\right|_{\lambda=0.5}=\frac{(1+\phi) \bar{h}}{2 \sigma f-(1+\phi) \bar{h}} ; \quad \bar{h}=\frac{\delta}{(1+\phi) n}$

Since $n=\frac{(1 / 2-Z)}{f}$ we get:

$\left.r_{1}\right|_{\lambda=0.5}=\left.r_{2}\right|_{\lambda=0.5} \equiv r=\frac{\delta}{\sigma(1-2 Z)-\delta}$

such that: $Y_{1}=Y_{2} \equiv Y=\frac{r}{2}+\frac{1}{2}=\frac{\sigma(1-2 Z)}{2[\sigma(1-2 Z)-\delta]}$ and $t_{1}=t_{2} \equiv t=\frac{r Z}{Y}=\frac{2 Z \delta}{(1-2 Z) \sigma}$

These results allow us to calculate the impact of changes of policy parameters on the endogenous variables of the model. The results are summarized in Table 4.

\section{Appendix III Derivation of equations (16) and (17)}

- The function $h_{1}$ transfers the pre-tax return to the post-tax return:

$h_{1}(\lambda \mid Z) \equiv \frac{1-t_{1}(\lambda \mid Z)}{1-t_{2}(\lambda \mid Z)}$

At the point of symmetry: $t_{1}=t_{2}=t, h_{1}(0.5 \mid Z)=1$, and $t_{1}^{\prime}(0.5 \mid Z)=-t_{2}^{\prime}(0.5 \mid Z)$, such that the derivative of $h_{1}$ simplifies to: $h_{1}^{\prime}(0.5 \mid Z)=-[2 /(1-t)] t_{1}^{\prime}(0.5 \mid Z)$. We therefore have to determine the impact of a change in the distribution of capital on the tax rate. Since $Y_{1}=r_{1} K_{1}+L_{1}$ and $r_{1} Z=t_{1} Y_{1}$ in the symmetric equilibrium:

$t_{1}^{\prime}(0.5 \mid Z)=t_{1}\left[\frac{r_{1}^{\prime}(0.5 \mid Z)}{2 r_{1} Y_{1}}-\frac{r_{1}}{Y_{1}}\right]$

Evaluating this expression at the margin at which no public goods are provided (such that the tax rate $\left.t_{1}=0\right)$ shows that $t_{1}^{\prime}(0.5 \mid 0)$ is identically 0 , such that $h_{1}^{\prime}(0.5 \mid 0)$ is identically 0 and at the margin the post-tax break-point analysis coincides with the pre-tax break-point analysis (note that this will simplify the break analysis below). 
- The function $h_{2}$ gives the relative return on capital. Using assumption 1 , the ratio of rewards to capital $r_{1} / r_{2}$ is given in (12'). It is obvious that $h_{2}(0.5 \mid Z)=1$. Taking the derivative of the function $h_{2}$ and evaluating it at the symmetric equilibrium gives:

$$
h_{2}^{\prime}(\lambda \mid Z)=\frac{-\left(b_{1}-b_{2}\right)\left(b_{1}+b_{2}-2 b_{3} Z\right)}{\left[b_{1} \lambda+b_{2}(1-\lambda)-b_{3} Z\right]^{2}}, \quad h_{2}^{\prime}(0.5 \mid Z)=\frac{-4\left(b_{1}-b_{2}\right)}{\left[b_{1}+b_{2}-2 b_{3} Z\right]}
$$

- The function $h_{3}$ gives the relative price index effect in the utility function:

$$
h_{3}(\lambda \mid Z) \equiv\left(\frac{P_{2}}{P_{1}}\right)^{\delta}=\left(\frac{(1-\lambda)+\phi \lambda-(1+\phi) Z}{\lambda+\phi(1-\lambda)-(1+\phi) Z}\right)^{\delta /(1-\sigma)}
$$

It is obvious that $h_{3}(0.5)=1$. Taking the derivative of $h_{3}$ and evaluating it at the symmetric equilibrium gives:

$$
h_{3}^{\prime}(0.5 \mid Z)=\frac{4 \delta(1-\phi)}{(\sigma-1)(1+\phi)(1-2 Z)}
$$

- Combining the results above implies that the break condition is equation (16) in the text. If there are no public goods, that is if $Z=0$ the solution for the free-ness of trade parameter, $\bar{\phi}$ say, that solves equation (16) is given by (see Forslid (1999), equation (13), or Forslid and Ottaviano (2001), equation (15)):

$$
\left.\phi_{\text {break }}\right|_{Z=0} \equiv \bar{\phi}=\frac{(\sigma-\delta)(\sigma-1-\delta)}{(\sigma+\delta)(\sigma+\delta-1)}
$$

We can determine the impact of the introduction of public goods at the margin by differentiating condition (16) with respect to $Z$ and evaluating the result at $Z=0$, $\lambda=0.5$, and $\phi=\bar{\phi}$ :

(A1) $\left.\frac{\partial h_{2}^{\prime}(0.5 \mid 0)}{\partial Z}\right|_{\phi=\bar{\phi}}+\left.\frac{\partial h_{3}^{\prime}(0.5 \mid 0)}{\partial Z}\right|_{\phi=\bar{\phi}}$

It can be shown that, as a function of $\phi$, equation (18) always cuts the horizontal axis from below if $\delta<\sigma-1$, which corresponds to the standard no-black-hole condition. ${ }^{12}$ The break point will be reached for a smaller value of the free-ness of trade index $\phi$ if equation (A1) is positive, and for a larger value if equation (A1) is negative. This is illustrated in figure 1. Straightforward, but tedious, calculations show that equation (A1) is positive if, and only if condition (17) in the text holds. 


\section{References}

Andersson, F. and R. Forslid (2003), "Tax competition and economic geography," Journal of Public Economic Theory 5: 279-203.

Baldwin, R. and R. Forslid (2002), "Tax Competition and the Nature of Capital", CEPR Discussion Paper, no. 3607, London.

Baldwin, R., R. Forslid, P. Martin, G. Ottaviano, and F. Robert-Nicoud (2003), Economic Geography and Public Policy, Princeton University Press, Princeton.

Baldwin, R. and P. Krugman (2004), "Agglomeration, integration and tax harmonization," European Economic Review 48: 1-23.

Brakman, S., H. Garretsen, and C. Van Marrewijk (2001), An introduction to geographical economics, Cambridge University Press, Cambridge, U.K.

Brakman, S., H. Garretsen, and C. Van Marrewijk (2002), "Location competition and agglomeration: the role of government spending," CESifo Working Paper Series, No. 775 .

Brülhart, M., and F. Trionfetti (2004), "Public expenditure, international specialisation, and agglomeration,” European Economic Review 48: 851-881.

CPB Netherlands Bureau for Economic Policy Analysis (2001), Capital Income Taxation in Europe, Trends and Trade-Offs, SDU Uitgevers, The Hague

Devereux, M., R. Griffith, and A. Klemm (2002), "Corporate income tax, reforms and tax competition,” Economic Policy 35, pp. 451-495.

Forslid, R. (1999), “Agglomeration with human and physical capital: an analytically solvable case, CEPR Discussion Paper, 2102, London.

Forslid, R. and G. Ottaviano (2001), "Trade and location: two analytically solvable cases," mimeo.

Forslid, R., and G. Ottaviano (2003), "An analytically solvable core-periphery model," Journal of Economic Geography 3: 229-240.

Garretsen, H. and J. Peeters (2006), "Capital Mobility, Agglomeration, and Corporate Tax Rates: Is the Race to the Bottom for Real?", mimeo, Utrecht University/De Nederlandsche Bank, Amsterdam.

Keen, M. and M. Marchand (1997), "Fiscal competition and the pattern of public spending," Journal of Public Economics 66: 33-53.

Krogstrup S., (2004), "Are Corporate Tax Burdens Racing to the Bottom in the European Union?", ERPU Working Paper Series, 2004-04. 
Neary, J.P. (2001), "Of hype and hyperbolas: introducing the new economic geography," Journal of Economic Literature 39, pp. 536-561.

Ottaviano, G. (2001), "Monopolistic competition, trade, and endogenous spatial fluctuations," Regional Science and Urban Economics 31: 51-77.

Samuelson, P.A. (1952), "Spatial price equilibrium and linear programming," American Economic Review 42: 283-303.

Sinn, H-W. (1990), "Tax harmonization and Tax competition in Europe," European Economic Review 34: 489-504.

Sinn, H-W (2004), "The new systems competition," Perspektiven der Wirtschaftspolitik 5: 23-38.

UNCTAD (1996), Incentives and Foreign Direct Investment, United Nations, New York. 
Tables and Figures

Table 1, Effective corporate income tax rates across the EU, \%

\begin{tabular}{|c|c|c|c|c|c|c|c|c|c|c|}
\hline & 1990 & 1991 & 1992 & 1993 & 1994 & 1995 & 1996 & 1997 & 1998 & 1999 \\
\hline Austria & 18 & 22 & 14 & 16 & 20 & 17 & 24 & 25 & 21 & 24 \\
\hline Belgium & 17 & 16 & 22 & 23 & 23 & 24 & 23 & 22 & 21 & 17 \\
\hline Denmark & 33 & 32 & 30 & 30 & 32 & 32 & 31 & 31 & 32 & 31 \\
\hline Finland & 45 & 37 & 34 & 24 & 26 & 27 & 28 & 28 & 28 & 28 \\
\hline France & 33 & 33 & 33 & 33 & 33 & 36 & 35 & 38 & 38 & 38 \\
\hline Germany & 48 & 49 & 49 & 44 & 41 & 41 & 41 & 40 & 40 & 41 \\
\hline Greece & 11 & 11 & 24 & 29 & 29 & 31 & 33 & 35 & 35 & 35 \\
\hline Ireland & 20 & 22 & 19 & 20 & 17 & 22 & 21 & 21 & 24 & 22 \\
\hline Italy & 38 & 41 & 47 & 50 & 44 & 46 & 45 & 43 & 44 & 40 \\
\hline Netherlands & 31 & 32 & 32 & 31 & 31 & 31 & 32 & 31 & 31 & 30 \\
\hline Portugal & 17 & 20 & 27 & 25 & 20 & 23 & 22 & 21 & 24 & 25 \\
\hline Spain & 27 & 28 & 29 & 27 & 25 & 24 & 26 & 26 & 26 & 29 \\
\hline Sweden & 31 & 32 & 30 & 19 & 28 & 27 & 28 & 28 & 28 & 28 \\
\hline U.K. & 33 & 31 & 31 & 30 & 30 & 30 & 30 & 29 & 29 & 29 \\
\hline Average & 28.7 & 29 & 30.2 & 27.7 & 28.4 & 29.3 & 29.9 & 29.8 & 30 & 29.8 \\
\hline Weight. Av.* & 35.5 & 36.1 & 37.3 & 35.3 & 34.1 & 35 & 35.1 & 34.8 & 34.9 & 34.6 \\
\hline St. dev. & 10.6 & 9.8 & 9.1 & 9.0 & 7.4 & 7.5 & 6.8 & 6.7 & 6.8 & 6.5 \\
\hline \multicolumn{11}{|c|}{$\begin{array}{l}\text { Source: CPB, 2001a, Capital Income Taxation in Europe, Trends and Trade-offs, The Hague, p. } \\
\text { 27; data for Luxembourg not available; *weighted by a country's GDP }\end{array}$} \\
\hline
\end{tabular}


Table 2 General government final consumption expenditure (\% of GDP)

\begin{tabular}{|c|c|c|c|c|c|c|c|c|c|c|}
\hline & 1960 & 1965 & 1970 & 1975 & 1980 & 1985 & 1990 & 1995 & 2000 & 2003 \\
\hline Austria & 13.4 & 13.8 & 15.2 & 17.8 & 18.5 & 19.6 & 18.9 & 20.4 & 19.2 & 18.7 \\
\hline Belgium & 15.6 & 16.1 & 16.9 & 21.2 & 23 & 22.9 & 20.3 & 21.4 & 21.2 & 22.8 \\
\hline Denmark & 13.6 & 17 & 20.9 & 25.3 & 27.3 & 25.9 & 25.6 & 25.8 & 25.3 & 26.5 \\
\hline Finland & 12.2 & 14 & 14.8 & 17.5 & 18.4 & 20.6 & 21.6 & 22.8 & 20.6 & 22.1 \\
\hline France & 16.7 & 16.9 & 17.3 & 19.5 & 21.5 & 23.7 & 22.3 & 23.9 & 23.2 & 24.3 \\
\hline Germany & & & & 21.7 & 21.7 & 21.3 & 19.7 & 19.8 & 19 & 19.3 \\
\hline Greece & 10.1 & 10.1 & 10.9 & 12.8 & 13.5 & 16.6 & 15.1 & 15.3 & 15.7 & 15.5 \\
\hline Ireland & 13.3 & 14.5 & 15.6 & 19.8 & 21.2 & 19.8 & 16.4 & 16.4 & 13.9 & $15.1^{*}$ \\
\hline Italy & 14.3 & 17 & 15.5 & 16.5 & 16.9 & 18.6 & 20.2 & 17.9 & 18.3 & 19.5 \\
\hline Netherlands & 16.3 & 18.8 & 19.9 & 23.8 & 25.3 & 24.3 & 23.5 & 24 & 22.7 & $24.5^{*}$ \\
\hline Portugal & 9.8 & 11.1 & 12.8 & 13.9 & 13.5 & 14.4 & 16.2 & 18.6 & 20.5 & $21.1^{*}$ \\
\hline Spain & 9.0 & 9.0 & 10.1 & 11.2 & 14 & 15.6 & 16.7 & 18.1 & 17.6 & 17.9 \\
\hline Sweden & 16.4 & 18.3 & 22.2 & 24.6 & 29.8 & 27.9 & 27.4 & 27.2 & 26.6 & 28.3 \\
\hline UK & 16.5 & 17.1 & 18 & 22.3 & 21.5 & 20.9 & 19.8 & 19.6 & 18.7 & 21.1 \\
\hline Average & 13.6 & 14.9 & 16.2 & 19.1 & 20.4 & 20.9 & 20.3 & 20.8 & 20.2 & 21.2 \\
\hline St dev. & 2.6 & 3.0 & 3.5 & 4.3 & 4.8 & 3.7 & 3.5 & 3.4 & 3.4 & 3.7 \\
\hline Min. & 9.0 & 9.0 & 10.1 & 11.2 & 13.5 & 14.4 & 15.1 & 15.3 & 13.9 & 15.1 \\
\hline Max. & 16.7 & 18.8 & 22.2 & 25.3 & 29.8 & 27.9 & 27.4 & 27.2 & 26.6 & 28.3 \\
\hline
\end{tabular}

Source: World Bank CD-ROM 2005; * = data for 2002; sequential maximum for France, Netherlands, Sweden, Denmark, Sweden, Denmark, and Sweden; sequential minimum for Spain, Greece, Spain, Portugal, Greece, Portugal,Greece, Ireland, and Greece. 
Table 3 Preferred Locations in North-West Europe

\begin{tabular}{l|l}
\hline \hline Regions: & Attractive because: \\
\hline \hline Niedersachsen (Germany) & $\begin{array}{l}\text { Close to Hannover. } \\
\text { Enough space, good accessibility. } \\
\text { Saarland (Germany) } \\
\text { Near highways leading to Ruhrgebiet, Subsidies to } \\
\text { start businesses, enough space, low land prices. } \\
\text { Picardie (France) }\end{array}$ \\
$\begin{array}{l}\text { Near Paris (airport), good accessibility, low land } \\
\text { prices. } \\
\text { Good infra-structure, always had a strong position } \\
\text { (path-dependency). }\end{array}$ \\
$\begin{array}{l}\text { Netherlands } \\
\text { Source: Dutch Ministry of Economic Affairs, Location Patterns of leading companies in } \\
\text { North-West Europe, 1999, p.36. }\end{array}$
\end{tabular}




\begin{tabular}{l|cccc}
\hline \hline & \multicolumn{4}{|c}{ Impact of rise in } \\
$\begin{array}{l}\text { Endogenous variable in } \\
\text { symmetric equilibrium }\end{array}$ & $\sigma$ & $\delta$ & $\phi$ & $Z$ \\
\hline$r=\frac{\delta}{\sigma(1-2 Z)-\delta}$ & - & + & 0 & + \\
$Y=\frac{\sigma(1-2 Z)}{2[\sigma(1-2 Z)-\delta]}$ & - & + & 0 & + \\
$p=f(Z)$ & 0 & 0 & 0 & - \\
$P=\left[\frac{(1+\phi)(1-2 Z)}{2}\right]^{\frac{1}{1-\sigma}} f(Z)^{\frac{\sigma}{\sigma-1}}$ & - & 0 & - & $?$ \\
$n=\frac{(1-2 Z)}{2 f(Z)}$ & 0 & 0 & 0 & $?$ \\
$t=\frac{2 Z \delta}{(1-2 Z) \sigma}$ & & & &
\end{tabular}


Figure 1 Break analysis $(\sigma=4, \delta=0.6)$

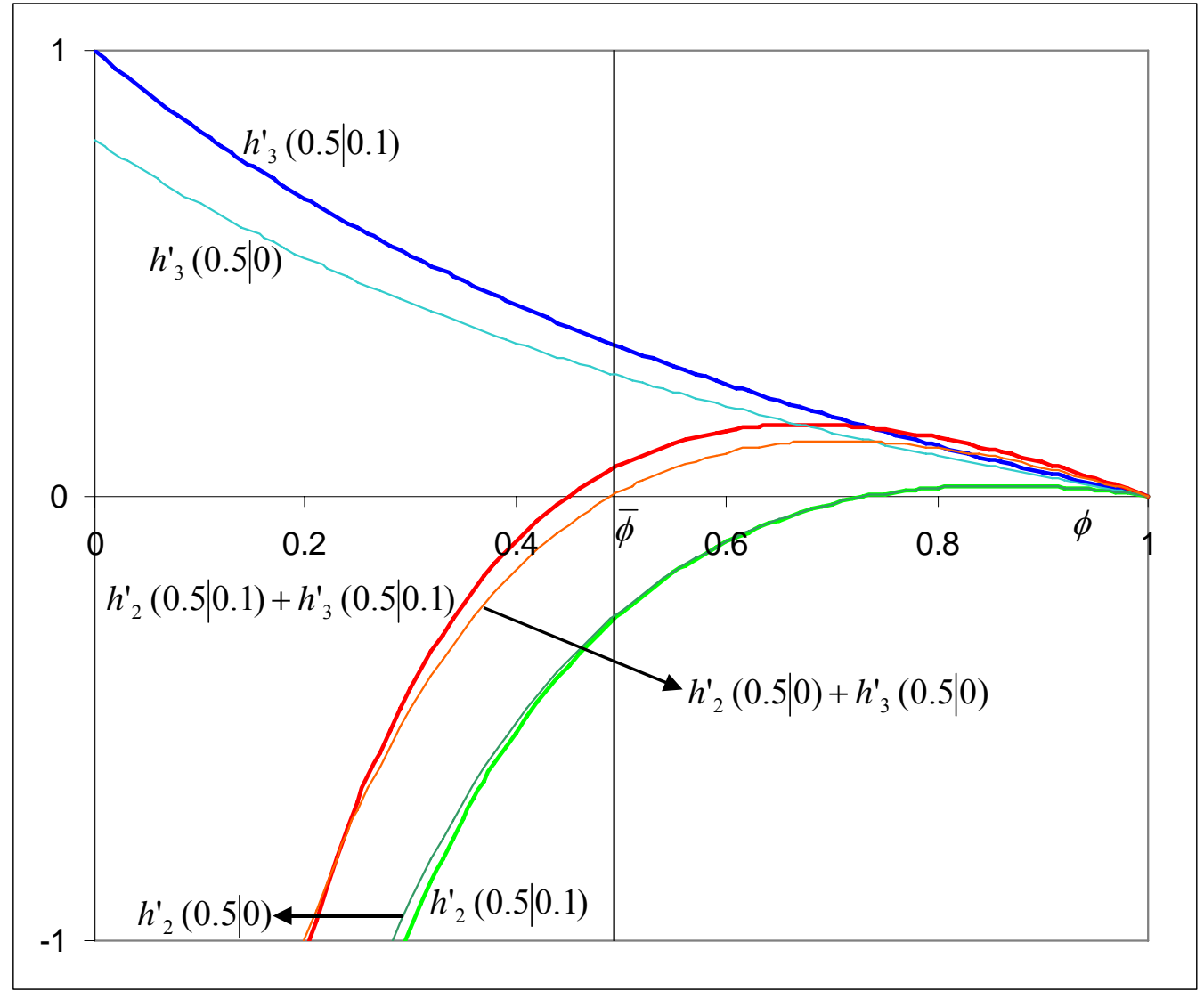


Figure 2 Marginal impact of introducing public goods on break-point

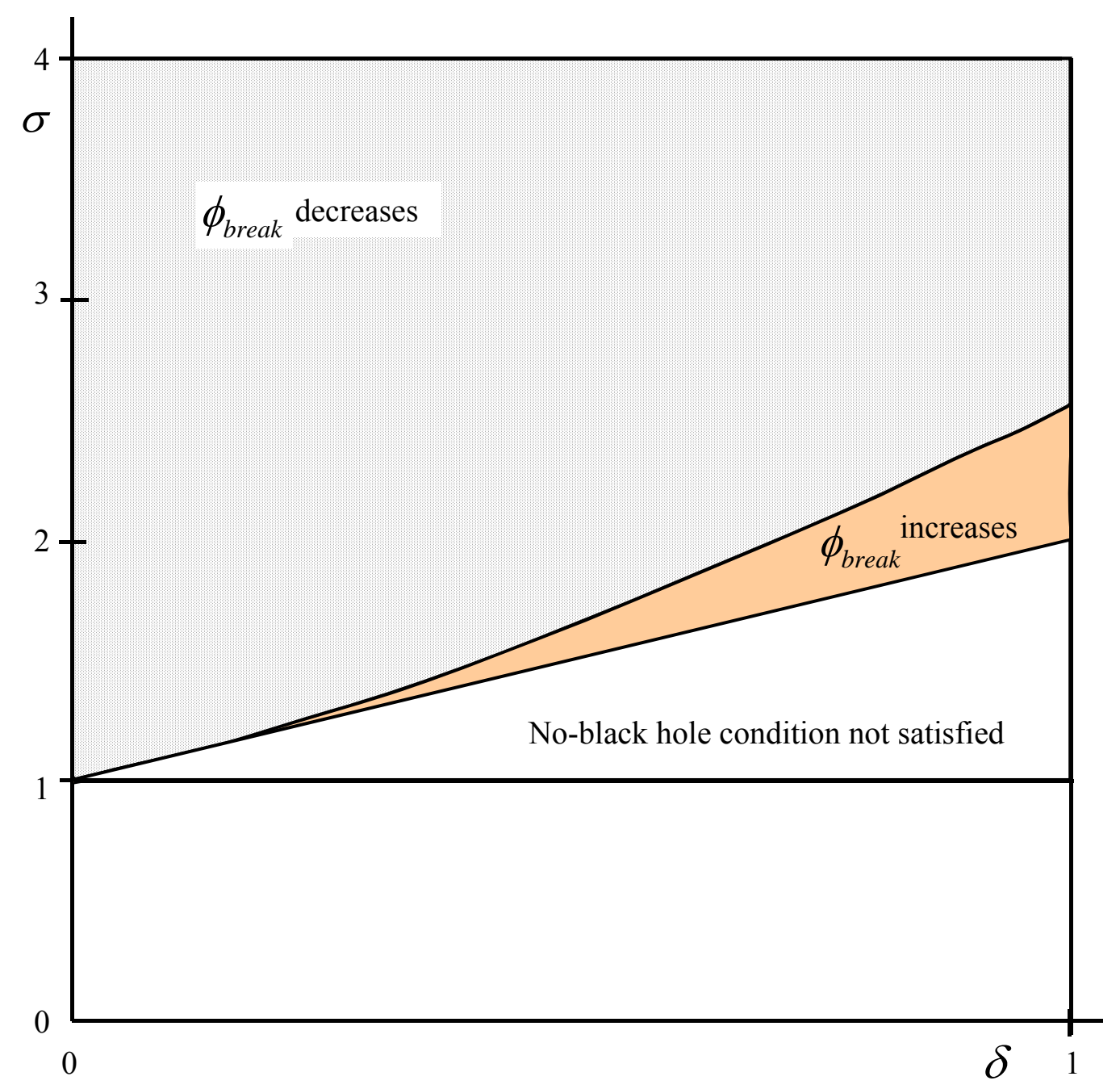


Figure 3 Introduction of Public Goods around Breakpoint

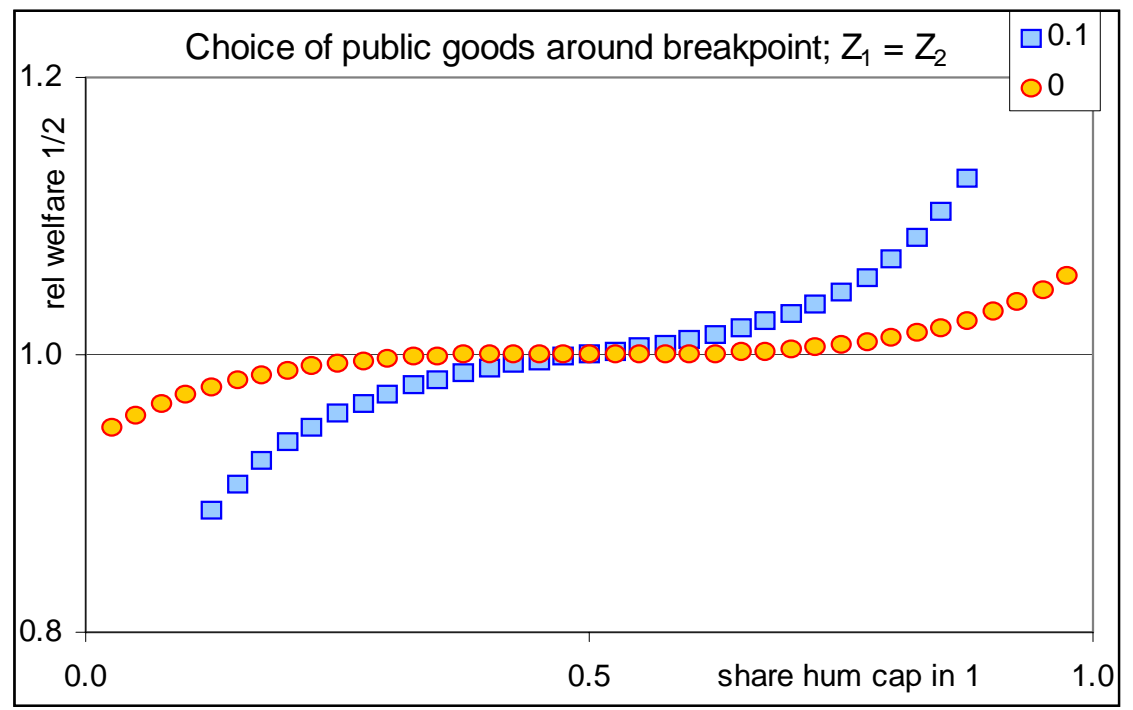

Parameter settings: $\eta_{\mathrm{i}}=1(\mathrm{i}=1,2) ; \delta=0.6 ; \sigma=3 ; \mathrm{Z}_{\mathrm{i}}=0.1$ (default 0$) ; \mathrm{L}_{\mathrm{i}}=0.5$ : $\phi$-break for $\mathrm{Z}=0$ is 0.359 
Figure 4 Asymmetric provision of public goods

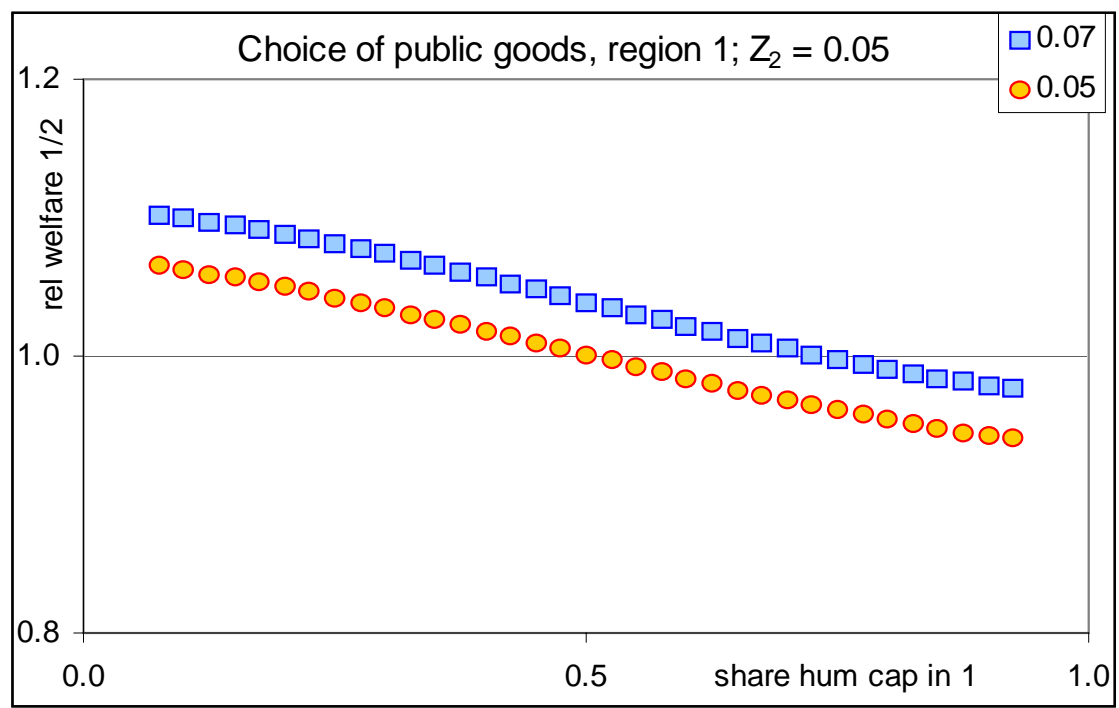

Parameter settings: $\eta_{\mathrm{i}}=1(\mathrm{i}=1,2) ; \delta=0.6 ; \sigma=4 ; \phi=0.4 ; \mathrm{Z}_{2}=0.05 ; \mathrm{Z}_{1}=0.05$ or $0.07 ; \mathrm{L}_{\mathrm{i}}=0.5$ 
Figure 5 Pushing the Public Goods Argument too Far...

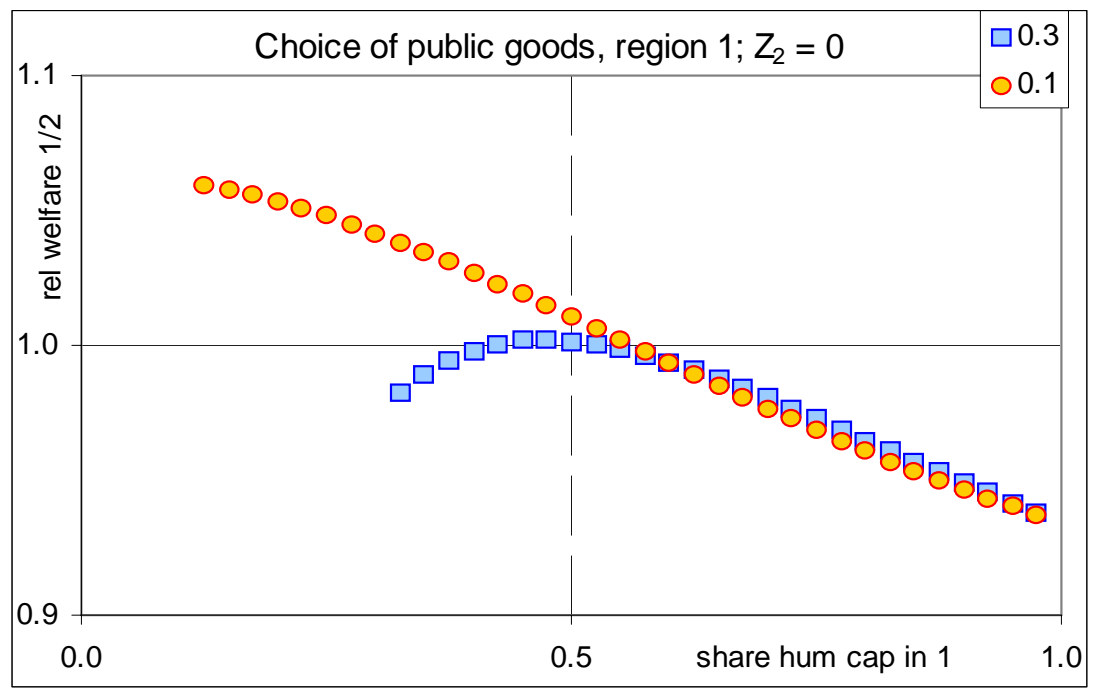

Parameter settings: $\eta_{\mathrm{i}}=0.1(\mathrm{i}=1,2) ; \delta=0.6 ; \sigma=4 ; \phi=0.4 ; \mathrm{Z}_{2}=0 ; \mathrm{Z}_{1}=0.1$ or $0.3 ; \mathrm{L}_{\mathrm{i}}=0.5$ 
*Respectively, Department of Economics, University of Groningen and CESifo; Utrecht School of Economics, Utrecht University and CESifo; Department of Economics, Erasmus University.

A first and rather different version of this paper has been published as CESifo Working Paper no. 775 (Brakman, Garretsen, and Van Marrewijk, 2002). We would like to thank Ron Davies, Jim Markusen, Gianmarco Ottaviano, Jolanda Peeters, Marc Schramm, Jan Egbert Sturm, Albert de Vaal, participants of the 2002 EEA conference in Venice, participants of the 2005 CESifo summer conference in Venice, and our referees, Ruud de Mooij en Rikard Forslid, for their useful comments.

Please send correspondence to: Charles van Marrewijk (vanmarrewijk@,few.eur.nl), Dept. of Economics, Erasmus University Rotterdam, PO Box 1738, 3000 DR Rotterdam, the Netherlands.

${ }^{1}$ Baldwin and Forslid (2002) is one of the first NEG papers to date that also deals with role of public goods alongside taxes.

${ }^{2}$ We do not address the difficult question about the most likely outcome of locationcompetition between governments. In the absence of ideal market conditions international welfare maximization is not guaranteed (see Sinn, 2004).

${ }^{3}$ These 4 countries are also the core countries in the sense that their share in total EU manufacturing production is about $75 \%$. This share remains fairly constant through the $1990 \mathrm{~s}$.

${ }^{4}$ Note that we do not claim that there is no tax competition at all in the EU. Sinn (2004), for instance, shows that the average tax burden for subsidiaries of US companies in the EU has decreased strongly in the various EU countries between 1986 and 1992. 
${ }^{5}$ The data used in Devereux et al, 2002, do not cover not all EU countries, for the actual data set used in this study and various measures of the corporate income tax rates and tax revenues, see:

http://www.ifs.org.uk/publications.php?publication_id=3210.

${ }^{6}$ To some extent, as shown below, the issue here is the difference between pure and pecuniary externalities. The former are absent in the standard geographical economics model.

${ }^{7}$ In the literature one finds various labels: skilled vs unskilled, human capital vs capital, labour vs capital. The precise label is not important for us as long one production factor is internationally mobile and the other is not.

${ }^{8}$ The main point here is to include a mobile and an immobile factor of production. The labelling of these two factors (unskilled versus skilled labor or labor versus capital) is not material as long as the mobile factor (be it skilled labor or capital) spends it income in the region where it is used for production; see in particular Forslid (1999, p.11) for a discussion of the importance of this assumption.

${ }^{9}$ Differentiating between labor and capital income taxation raises the complication why to tax the mobile factor at all, see also Sinn (2004).

10 The net effect on welfare cannot be discussed as a change in the elasticity of substitution affects the utility function itself. This also holds for a change in the share of income spent on manufactures.

${ }^{11}$ This expression readily simplifies to the Forslid-Ottaviano model if there are no public goods, see e.g. Ottaviano (2001), equation (10).

12 This condition is somewhat less restrictive than the no-black hole condition in Fujita, Krugman, and Venables (1999). See also the appendix of Ottaviano (2001). 